\title{
Power Consumption Modeling of Data Center IT Room with Distributed Air Flow
}

\author{
Xiaojing Zhang, Therese Lindberg, Krister Svensson, Valeriy Vyatkin, and Arash Mousavi
}

\begin{abstract}
Modern data centers are characterized by large sizes, high energy consumption and complexity involving IT, power supply, ventilation and cooling. Data center energy efficiency is a major concern for data center design and operation. To improve data center energy efficiency through efficient cooling and ventilation, advanced process control and optimization, process models to describe the process power consumption are required. In this work, data center power consumption models are investigated. A concept of distributed air flow control is presented. The objective is to develop a comprehensive data center power consumption model to describe IT room, computer room air handling (CRAH), data center ventilation and cooling characteristics as well as distributed air flow control. Data center operation scenarios with uneven IT load are simulated. Results show that the distributed air flow control can save the cooling energy significantly.
\end{abstract}

Index Terms-Server, rack, CRAH, model, power consumption.

\section{INTRODUCTION}

The worldwide energy consumption of data centers increased 56\% between 2005 and 2010, and reached 237 terawatt hours (TWh) in 2010, accounting for over $1 \%$ of the world's electricity usage [1]. It is estimated that the market was worth about $\$ 128$ billion in 2012, and will grow by about 5 percent yearly to reach $\$ 152$ billion in 2016 [2]. Meanwhile there is a trend to build mega-data centers with capacity over $20 \mathrm{MW}$. Energy efficiency becomes an important issue in these mega-data centers. We have made an investigation of 10 random data centers, which revealed the energy consumption by cooling data center IT equipment is between $30 \%$ and $55 \%$ of total energy consumption. Cooling and ventilation system consumes on average $39 \%$ of the total energy consumption. Therefore, how to improve power utilization, reduce operation costs and increase energy efficiency must be taken into account before building up a new data center.

Manuscript received August 28, 2015; revised December 23, 2015. This work was from a Joint project with Karlstad University and Luleå University, Sweden.

Xiaojing Zhang is with $\mathrm{ABB}$ Corporate Research in Västerås, Sweden (e-mail: xiaojing.zhang@se.abb.com).

Therese Lindberg and Krister Svensson are with the Department of Engineering and Physics at Karlstad University, Sweden.

Valeriy Vyatkin is with the Department of Computer Science, Electrical and Space Engineering at Luleå University of Technology, Sweden and the Department of Electrical Engineering and Automation, Aalto University, Finland.

Arash Mousavi is with the Department of Computer Science, Electrical and Space Engineering at Luleå University of Technology, Sweden.
A modern data center has a large room with many rows of racks filled with servers and other IT equipment used for process, store and transmit digital information. Previous work from Grenoble Institute of Technology provided system models for IT system and data center cooling system including server modelling and power equipment losses [3]. The model was used to build a simulation tool to estimate and simulate the energy consumption of all equipment in the data center. Another approach is to combine computational fluid dynamics and heat transfer modelling was proposed by Joshi and Kumar [4], which gives a detailed description of the flow and the temperatures across the room. A limitation to this method is its complexity and high computational intensity. The energy consumption model of the different cooling system components was developed by Iyengar and Schmidt [5], [6]. They introduced a relationship between the flow rates of the CRAH units and the server racks Pelley et al. published data center model included an idle consumption of the CRAH units [7]. Beitelmal et al. further developed chiller and cooling tower model [8], while Demetriou et al. included hydraulic modelling of the pipe network in the model of the cooling system [9]. Recently published model from Cupertino et al. was focused on workload modelling [10].

There are several approaches to increase the datacenter energy efficiency. One of them is through process modeling, simulation, control and optimization, which is used in this work. Several scenarios are simulated and compared for various server IT load and ventilation methods. Cooling energy saving potential is identified.

\section{Distributed AIR FlOW}

Many data centers operate under uneven IT load and cooling load over different racks. A typical data center with the most common used raised floor ventilation is shown in Fig. 1. The data center operates with idle severs and servers with different server utilizations. To meet the cooling needs of all servers and racks and to avoid local overcooling, one of approaches is to apply a new concept, the distributed air flow control by dividing a data center in different zones and with controllable ventilation systems. With the distributed air flow control, different amounts of air flow are supplied to different zones across the data center based on local cooling load. In this way, overcooling can be reduced or even eliminated, which results in a significant energy saving. The size of these zones (the number of racks in each zone), is related to size of the data centers and how we design the ventilation and air flow system. The distributed air flow control can be implemented in a traditional raised-floor data center or air flow control with other type of data center ventilation 
systems.

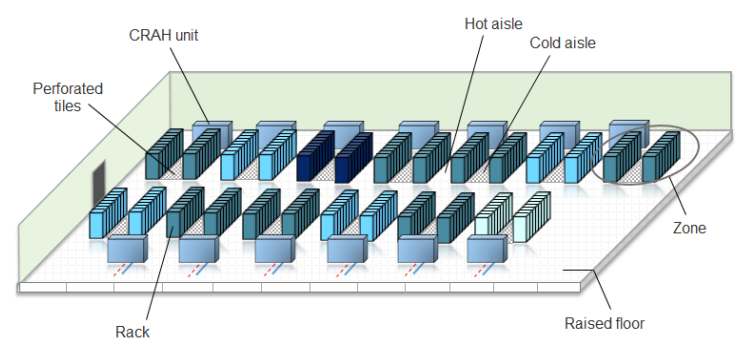

Fig. 1. Data center with uneven IT utilization.

\section{DAta Center Power Consumption Modeling}

A modern data center consists of several complex systems comprising the IT equipment as the main heat source and cooling equipment, ventilation system as heat sink. A number of approximations and assumptions are made to simplify the modeling effort including the change in the temperature between CRAH outlet temperature and rack inlet temperature is neglected; the server fans are assumed to be able to, and operate on the principle of, keeping the outlet temperature constant; the air flow rate through a rack is evenly distributed and all servers get the same flow rate; and the change in kinetic energy can be neglected in all energy balances. The air supply to the racks is assumed to be independent of the rack location and the distance to the CRAH unit. For traditional raised floor cooling air supply, the flow rate is approximated as uniform within one zone. This means that the flow rate abruptly changes at the zone boundaries. Similarly, the flow rate within one rack is approximated as uniform in the plane perpendicular to the flow direction.

Data center total cooling power consumption $\dot{W}_{\text {cooling }}$ is sum of each component of the cooling system, the server fans in the racks, the fans in the CRAH units and the cooling tower, the compressor in the chiller and the pumps in the building chilled water loop and the cooling tower.

$$
\begin{gathered}
\dot{W}_{\text {cooling }}=\dot{W}_{\text {rack_tot }}+\dot{W}_{C R A H_{-} \text {tot }}+\dot{W}_{B C W}+\dot{W}_{\text {chiller }}+\dot{W}_{C T} \\
P U E=\frac{\dot{W}_{I T_{-} \text {tot }}+\dot{W}_{\text {cooling }}+\dot{W}_{\text {other }}}{\dot{W}_{I T_{-} \text {tot }}}
\end{gathered}
$$

where $\dot{W}_{\text {rack }- \text { tot }}$ is the total power consumption of the racks and $\dot{W}_{C R A H_{-} t o t}, \dot{W}_{B C W}, \dot{W}_{\text {chiller }}$ and $\dot{W}_{C T}$ are the total power consumption of the CRAH units, the building chilled water, the chiller and the cooling tower, respectively. $\dot{W}_{I T_{-} t o t}$ is the total power consumption of the servers and $\dot{W}_{\text {other }}$ is other power consuming components including lighting and power losses in the UPS and PDU:s. The power consumption of all components of the cooling system except the chiller is calculated with the following mechanical efficiency equation, [11]:

$$
\dot{W}=\frac{\dot{V} \Delta P}{\eta}
$$

where $\dot{V}$ is the flow rate, $\eta$ is the efficiency of the device. $\Delta P$ is pressure drop of the component which can be determined by:

$$
\Delta P=C_{L}^{2} \dot{V}^{2}
$$

\section{A. Server Power Consumption}

The server power consumption, $\dot{W}_{\text {server }}$, is modelled as linear with the server utilization, $u$, for different zones. Idle power is related to the maximum power consumption.

$$
\begin{gathered}
\dot{W}_{\text {server }}=\dot{W}_{\text {serv_idle }}+\left(\dot{W}_{\text {serv_peak }}-\dot{W}_{\text {serv_idle }}\right) u_{\text {zone_y }} \\
\dot{W}_{\text {serv_idle }}=\delta_{\text {idle_power }_{-}} \dot{W}_{\text {serv_peak }} \\
\dot{W}_{\text {IT_tot }}=\sum_{y} \delta_{\text {zone_y }_{-} N_{\text {servers }}} \dot{W}_{\text {servers }}
\end{gathered}
$$

where $\dot{W}_{\text {serv_idle }}, \dot{W}_{\text {serv_peak }}$ and $\dot{W}_{I_{-} \text {tot }}$ are the power consumptions of an idle server, a server at peak load and the total server power consumption, respectively, $\delta_{\text {idle_power }}$ is the fraction of the idle power consumption to the peak load power consumption and $N_{\text {servers }}$ is the number of servers. Index $y$ represent the different zone types, described in Section IV.

\section{B. The IT Room}

There are two power consuming cooling components in the IT room for a data center using a CRAH system; the server fans in the racks and the fans in the CRAH units. They are both modelled with the mechanical efficiency. The pressure drop and the flow rate in the racks and the CRAH units are depended on ventilation and air flow design; and relation between CRAH air flow and the flow rate in the BCW loop.

\section{1) CRAH pressure drop}

The pressure drop over a CRAH unit includes a correction factor for inclusion of the under-floor plenum, $\left(1+\beta_{C R A H}\right)$ is adapted from [12]:

$$
\Delta P_{\text {CRAH }}=\left(C_{L, C R A H_{-} \text {int }}\left(1+\beta_{C R A H}\right)\right)^{2} \dot{V}_{C R A H}^{2}
$$

where $C_{L, C R A H}$ and $\dot{V}_{C R A H}$ is the pressure loss coefficient and the flow rate of a CRAH unit, respectively.

The pressure drop over a rack consists of the pressure drop over the front doors, rear doors and over the servers [13].

$$
\begin{aligned}
& \Delta P_{\text {trad_rack }}=\Delta P_{\text {front }}+\Delta P_{\text {server }}+\Delta P_{\text {rear }}= \\
& \left(C_{L, \text { front }}^{2}+C_{L, \text { rear }}^{2}\right) \dot{V}_{\text {rack }}^{2}+C_{L, \text { server }}^{2}\left(\frac{\dot{V}_{\text {rack }}}{N_{\text {servers/rack }}}\right)^{2}
\end{aligned}
$$

where $C_{L, \text { front }}, C_{L, \text { rear }}$ and $C_{L, \text { server }}$ are the pressure loss coefficients of the front and rear doors and the servers, $\dot{V}_{\text {rack }}$ is the rack flow rate and $N_{\text {servers rack }}$ is the number of servers in the rack.

\section{2) Flow rate relations}

The main modelling difference between traditional air 
supply and the distributed airflow control is how the CRAH flow rate relates to the rack flow rate. With traditional air supply, all CRAH units supply a large amount of airflow, based on the servers with the maximum cooling load (highest utilization). With the distributed airflow control, each CRAH units may supply different amounts of cooling air, depending server IT load in each zone. A general relation which relates CRAH flow rate to rack flow rate for all zones with the distributed airflow control is given in equation (9). It takes regard to flow losses due to leakage and flow bypass due to cold and hot air mixing over the rack, which happens to traditional cold aisle/hot aisle ventilation design.

$$
\dot{V}_{C R A H}=\frac{N_{\text {rack }} \dot{V}_{\text {rack }}}{N_{\text {CRAH }}\left(1-\delta_{\text {leakage }}\right)\left(1-\delta_{\text {bypass }}\right)}
$$

where $N_{\text {rack }}$ and $N_{\text {CRAH }}$ is the number of racks and CRAH units and $\delta_{\text {leakage }}$ and $\delta_{\text {bypass }}$ is the fractions of the flow lost to leakage and the flow bypass.

3) Flow rate for traditional air supply and the distributed airflow control

The equations for the rack flow rate is identical for the traditional air supply and the distributed airflow control. The difference lies in the fact that the CRAH flow rate is the same for all zones in the traditional air supply, while for the distributed airflow control, the flow rates are calculated for several types of zones with idle server or different server utilization. Rack energy balance is required to relate the rack temperatures, $T_{\text {rack_out }}$ and $T_{T_{\text {rack_in }}}$, to the flow rate [14]:

$$
\dot{V}_{\text {rack }}=\frac{\dot{Q}_{\text {rack }}}{\rho_{\text {air }} c_{p, \text { air }}\left(T_{\text {rack_out }}-T_{\text {rack_in }}\right)}
$$

where $\dot{Q}_{\text {rack }}$ is the heat load of one rack, which is the same as the power consumption of all servers in the rack, and $c_{p, a i r}$ and $\rho_{\text {air }}$ is the specific heat and density of the air. A fluid mixture equation of the rack outlet air flow and the bypass flow relates the rack temperatures to the $\mathrm{CRAH}$ inlet temperature is given as:

$$
T_{\text {CRAH_in }}=\delta_{\text {bypass }} T_{\text {rack_in }}+\left(1-\delta_{\text {bypass }}\right) T_{\text {rack_out }}
$$

\section{4) Rack flow rate}

Equation (11) can be used to calculate the rack flow rate once the CRAH flow rate is known. Otherwise, the rack flow rate can be derived from the heat exchanger equations based on the rack energy balance and a fluid mixture equation of the rack outlet flow and the bypass flow, $\dot{V}_{\text {bypass }}$, where the bypass in unknown. The fluid mixture equation and the bypass flow are given as:

$$
\begin{gathered}
T_{\text {CRAH_in }}=\frac{\dot{V}_{\text {rack }} T_{\text {rack_out }}+\dot{V}_{\text {bypass }} T_{\text {rack_in }}}{\dot{V}_{\text {rack }}+\dot{V}_{\text {bypass }}} \\
\dot{V}_{\text {bypass }}=\frac{N_{C R A H}\left(1-\delta_{\text {leakage }}\right)}{N_{\text {rack }}} \dot{V}_{C R A H}-\dot{V}_{\text {rack }}
\end{gathered}
$$

The equation to solve for the rack flow rate is:

$$
\begin{gathered}
\dot{V}_{\text {rack }}=\frac{\dot{Q}_{\text {rack }}\left(1-J \dot{V}_{\text {rack }}+K\right)}{\rho_{\text {air }} c_{\text {p,air }}\left(T_{\text {rack_out }}(1+K)-I\right)} \\
I=\frac{\in_{H E} C_{\text {min }} T_{H_{2} O_{-} i n}}{\epsilon_{H E} C_{\text {min }}-C_{\text {air }}} \\
J=\frac{\left.N_{\text {rack }}\right) \dot{V}_{C R A H}}{N_{C R A H}\left(1-\delta_{\text {leakage }}\right.} \\
K=\frac{C_{\text {air }}}{\epsilon_{H E} C_{\text {min }}-C_{\text {air }}}
\end{gathered}
$$

where the heat exchanger effectiveness is modeled separately.

\section{5) CRAH heat exchanger effectiveness}

$\mathrm{CRAH}$ heat exchanger is modelled as a single-pass cross-flow heat exchanger with both fluids unmixed. The heat exchanger effectiveness model is adapted from [15][16]:

$$
\begin{aligned}
& \epsilon_{H E}=1-\exp \left(\frac{N T U^{0,22}}{C_{r}}\left(e^{-C r N T U^{0.78}}-1\right)\right) \\
& N T U=\frac{U A}{C_{\text {min }}}=\frac{U A}{\left(\rho c_{p} \dot{V}\right)_{\text {min }}} \\
& C_{r}=\frac{C_{\min }}{C_{\max }}=\frac{\left(\rho c_{p} \dot{V}\right)_{\min }}{\left(\rho c_{p} \dot{V}\right)_{\max }} \\
& \epsilon_{H E}=\frac{C_{\text {air }}\left(T_{C R A H_{-} \text {in }}-T_{\text {CRAH_out }}\right)}{C_{\text {min }}\left(T_{C R A H_{-} \text {in }}-T_{H_{2} O_{-} \text {in }}\right)}
\end{aligned}
$$

where $U$ is the overall heat transfer coefficient, $A$ is the heat transfer surface area, $T_{\mathrm{H}_{2} \mathrm{O}_{-} \text {in }}$ is the temperature of the $\mathrm{BCW}$ water entering the $\mathrm{CRAH}$ heat exchanger, $T_{\text {CRAH out }}$ is the temperature of the air leaving it and $C_{\min }, C_{\max }$ and $C_{\text {air }}$ are the smallest and the largest heat capacity rates and the heat capacity rate of the air flow, respectively.

Depending on which side of the CRAH heat exchanger has the minimum heat capacity, two equations for CRAH flow rate are presented in equation (19) and (20). With $C_{\min }$ on the air side of the heat exchanger, the CRAH flow rate is expressed as:

$$
\begin{aligned}
& 1-\exp \left(\frac{B^{0.22} \dot{V}_{B C W}}{D \dot{V}_{C R A H}^{1.22}}\left(e^{-D B^{0,78} \frac{\dot{V}_{C R A H}^{0,22}}{\dot{V}_{B C W}}}-1\right)=\right. \\
& \frac{A^{\prime} \dot{Q}_{\text {rack }}}{\left(T_{\text {rack_out }}-T_{H_{2} O_{-} i n}\right) \dot{V}_{C R A H}-\delta_{\text {bypass }} A \dot{Q}_{\text {rack }}}
\end{aligned}
$$

where $\dot{V}_{B C W}$ is the flow rate in the building chilled water. With $C_{\min }$ on the water side of the heat exchanger, the CRAH flow rate is: 


$$
\begin{aligned}
& 1-\exp \left(\frac{F^{0,22} D \dot{V}_{C R A H}}{\dot{V}_{B C W}^{1.22}}\left(e^{-\frac{F^{0,78} \dot{V}_{B C W}^{0,22}}{D \dot{V}_{C R A H}}}-1\right)\right)= \\
& \frac{E \dot{V}_{\text {CRAH }} \dot{Q}_{\text {rack }}}{\dot{V}_{B C W}\left(\left(T_{\text {rack_out }}-T_{\mathrm{H}_{2} \mathrm{O}_{-} \text {in }}\right) \dot{V}_{\text {CRAH }}-\delta_{\text {bypass }} A \dot{Q}_{\text {rack }}\right)} \\
& A=\frac{N_{\text {rack }}}{\rho_{\text {air }} c_{p, \text { air }} N_{\text {CRAH }}\left(1-\delta_{\text {leakage }}\right)\left(1-\delta_{\text {bypass }}\right)} \\
& A^{\prime}=\frac{N_{\text {rack }}}{\rho_{\text {air }} c_{\text {p,air }} N_{C R A H}\left(1-\delta_{\text {leakage }}\right)} \\
& B=\frac{(U A)_{C R A H}}{\rho_{\text {air }} c_{p, a i r}} \\
& D=\frac{\rho_{a i r} c_{p, a i r} N_{C R A H}}{\rho_{\mathrm{H}_{2} \mathrm{O}} c_{p, \mathrm{H}_{2} \mathrm{O}}} \\
& E=\frac{\rho_{\text {air }} c_{p, a i r} N_{C R A H} A^{\prime}}{\rho_{\mathrm{H}_{2} \mathrm{O}} c_{p, \mathrm{H}_{2} \mathrm{O}}} \\
& F=\frac{(U A)_{C R A H} N_{C R A H}}{\rho_{\mathrm{H}_{2} \mathrm{O}} c_{p, \mathrm{H}_{2} \mathrm{O}}}
\end{aligned}
$$

The lighting power consumption assumes a known consumption per unit area, $(P d)_{\text {lights }}$, and relates this to the data center floor area through the number of racks and the area occupied by one rack, $A_{\text {rack }},[17]$.

$$
\dot{W}_{\text {lights }}=2.1 N_{\text {rack }} A_{\text {rack }}(P d)_{\text {lights }}
$$

The power equipment losses are assumed to be linear with their load and are:

$$
\begin{aligned}
& \dot{W}_{P D U, \text { loss }}=\delta_{P D U_{-} \text {loss }}\left(\dot{W}_{I T_{-} \text {tot }}+\dot{W}_{\text {rack_tot }}\right) \\
& \dot{W}_{U P S, l o s s}=\delta_{U P S_{-} l o s s}\left(\dot{W}_{P D U}+\dot{W}_{C R A H_{-} t o t}\right)= \\
& \delta_{U P S_{-} \text {loss }}\left(\frac{\dot{W}_{I T_{-} t o t}+\dot{W}_{\text {rack_tot }}}{1-\delta_{P D U_{-} \text {loss }}}+\dot{W}_{C R A H_{-} t o t}\right)
\end{aligned}
$$

\section{6) CRAH and rack power consumption}

The total power consumption of rack and CRAH units can be calculated using equation (3) together with the equations for pressure drops and flow rates presented in previous sections and the fan efficiency, $\eta_{C R A H_{-} \text {fan }}$ or $\eta_{\text {rack_fan }}$. For the traditional air supply, total power consumption of CRAH unites is the summation of all units.

$$
\dot{W}_{\text {CRAH_tot }}=N_{C R A H} \frac{\dot{V}_{C R A H} \Delta P_{C R A H}}{\eta_{C R A H_{-} f a n}}
$$

For the approach with the distributed airflow control, different types of zones $(y)$ need to be added to get the total CRAH power consumption.

$$
\dot{W}_{\mathrm{CRAH}_{-} \mathrm{tot}}=\sum_{y} \delta_{\text {zone }_{-} y} N_{\mathrm{CRAH}} \frac{\dot{V}_{\mathrm{CRAH_{- }}} \Delta P_{\mathrm{CRAH}}}{\eta_{\mathrm{CRAH}_{-} \mathrm{fan}}}
$$

where $\dot{V}_{\mathrm{CRAH}_{-} y}$ is the flow rate in a zone of type $y$ and $\delta_{\text {zone }_{-} y}$ is the fraction of zones of specified type. Similarly, the total rack power consumption is expressed in equation (24) which is valid for both the traditional air supply and the distributed air flow control.

$$
\dot{W}_{\text {rack_tot }}=\sum_{y} \delta_{\text {zone_y }_{-}} N_{\text {rack }} \frac{\dot{V}_{\text {rack_y }} \Delta P_{\text {trad_rack }}}{\eta_{\text {rack_fan }_{-}}}
$$

\section{Other Sources Contributing to the Heat Load}

The model includes other three contributors to the data center heat load, the lighting and losses in the power equipment (UPS and PDU).

where $\delta_{P D U_{-} \text {loss }}$ and $\delta_{U P S_{-} \text {loss }}$ are the loss fraction of the power in the PDU and UPS and $\dot{W}_{P D U}$ is the power consumption of the PDU:s.

\section{Building Chilled Water, Chiller and Cooling Tower}

The power consumption of the building chilled water pumps and the pumps and fans in the cooling tower are calculated from equation (3) and (4). The chiller power consumption is calculated from COP, [12]:

$$
\dot{W}_{\text {chiller }}=\frac{\dot{Q}_{\text {chiller }}}{C O P_{\text {chiller }}}
$$

where $\dot{Q}_{\text {chiller }}$ is the heat load on the chiller and comprises all the power consumed in the cooling chain including the servers, the racks, the CRAH units, the lighting, power equipment losses and the building chilled water.

\section{Simulation ScEnARIOS AND REsults}

A data center with 208 racks is simulated. Each CRAH has capacity of $452 \mathrm{~kW}$. Cooling design is with redundancy of $\mathrm{N}+1$. All servers were assumed to be identical, making the differences in heat load solely depended on the different server utilizations. Each rack contains 42 servers.

The simulation scenarios are based on the idea that all racks are divided into zones where different zones may have different server utilizations. 13 zones are defined and each zone consists of 16 server racks. The zone distribution is showed in Fig. 1 with different colors.

Three scenarios, Even load, Idle server and Uneven load, were studied. A base sever utilization of 0.85 is applied for all three scenarios. In Even load, all servers in all zones have the same utilization of 0.85 . In Idle server, four zones are idle and 9 zones are with the utilization of 0.85. Uneven load contains four groups of zones with different utilizations, which can be seen in Table 1. Both Idle server and Uneven load include two cases, with the distributed air flow control 
and without distributed air flow control.

TABLE I: SIMULATION SCENARIOS

\begin{tabular}{lll}
\hline \hline Scenario & Utilization & Fraction of zones \\
\hline Even load & 0.85 & 1 \\
\hline Idle server & 0 & $4 / 13$ \\
(with control and & 0.85 & $9 / 13$ \\
without control) & & \\
\hline Uneven load & 0.25 & $1 / 13$ \\
(with control and & 0.65 & $4 / 13$ \\
without control) & 0.85 & $7 / 13$ \\
& 0.90 & $1 / 13$ \\
\hline \hline
\end{tabular}

The developed model calculates the cooling power consumption and provides process physical relations for a number of process parameters. Fig. 2 shows CRAH flow rate and total cooling power consumption as a function of the building chilled water (BCW) flow rate which is critical parameter affecting the air flow rate needed to be supplied by CRAH units to keep a constant rack outlet temperature. With the rack outlet temperature set point of $37^{\circ} \mathrm{C}$, there is an optimal BCW flow rate around $0.2 \mathrm{~m} 3 / \mathrm{s}$. If $\mathrm{BCW}$ flow rate is less than $0.2 \mathrm{~m} 3 / \mathrm{s}$, both CRAH flow rate and $\mathrm{CRAH}$ power consumption increase rapidly due to increase of the CRAH fan power. For high BCW flow rate, the power consumption of the BCW pump system increases and dominates the total cooling power consumption.

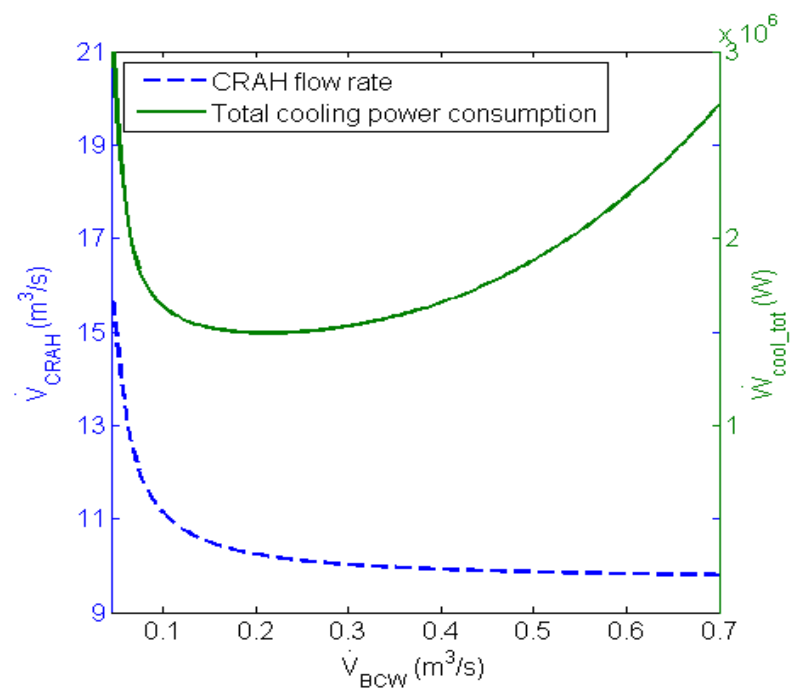

Fig. 2. CRAH flow rate and total cooling power consumption for varying $\mathrm{BCW}$ flow rate.

The effect of the rack outlet temperature on the total cooling power consumption is shown in Fig. 3 for all scenarios and with the traditional air supply and the distributed air flow control. In Fig. 3 (a), traditional air supply and distributed air flow control curves overlap, which showed that there is no difference when the server IT load are evenly distributed. In Fig. 3 (b) and (c), it can be seen that for traditional air supply, the total cooling power consumption rises gradually with set point temperature decrease and it rises rather rapidly for the set point temperature lower than about $37^{\circ} \mathrm{C}$. This makes it costly to introduce large safety margins in order to stand better prepared for sudden increase in heat load or to lower the effect of local hot spots. Apparent energy saving can be achieved by apply the distributed air flow control for Idle server and Uneven load with conmen data center rack outlet temperature. The energy saving is even more significant when the rack outlet temperature is reduced.

CRAH and total cooling power consumptions are presented in Fig. 4 and 5. Significant energy saving is observed for Idle server and Uneven load with the distributed air flow control comparing with the traditional air supply. This is because CRAH units do not provide overcooling for the zones with idle servers and lower server utilization. For the traditional air supply, significant energy is simply lost due to lack of cooling control of IT load variation for different server racks. Chiller power consumption is mainly depended on different rack heat load. There are no advantages for the distributed air flow control for even IT load. However, most data centers operate under uneven load with even idle servers. In such cases, the distributed air flow control can be applied to save energy. The total cooling power consumption not only depends on racks, CRAH unite and chillers, but also the power consumption of the building chilled water pumps and the pumps and fans of the cooling tower. It gives the same trend for CRAH in Fig. 4. For studied scenarios, the power consumption reduced by $15 \%$ for Idle server by applying the distributed air flow control and reduced by $16 \%$ for Uneven load.
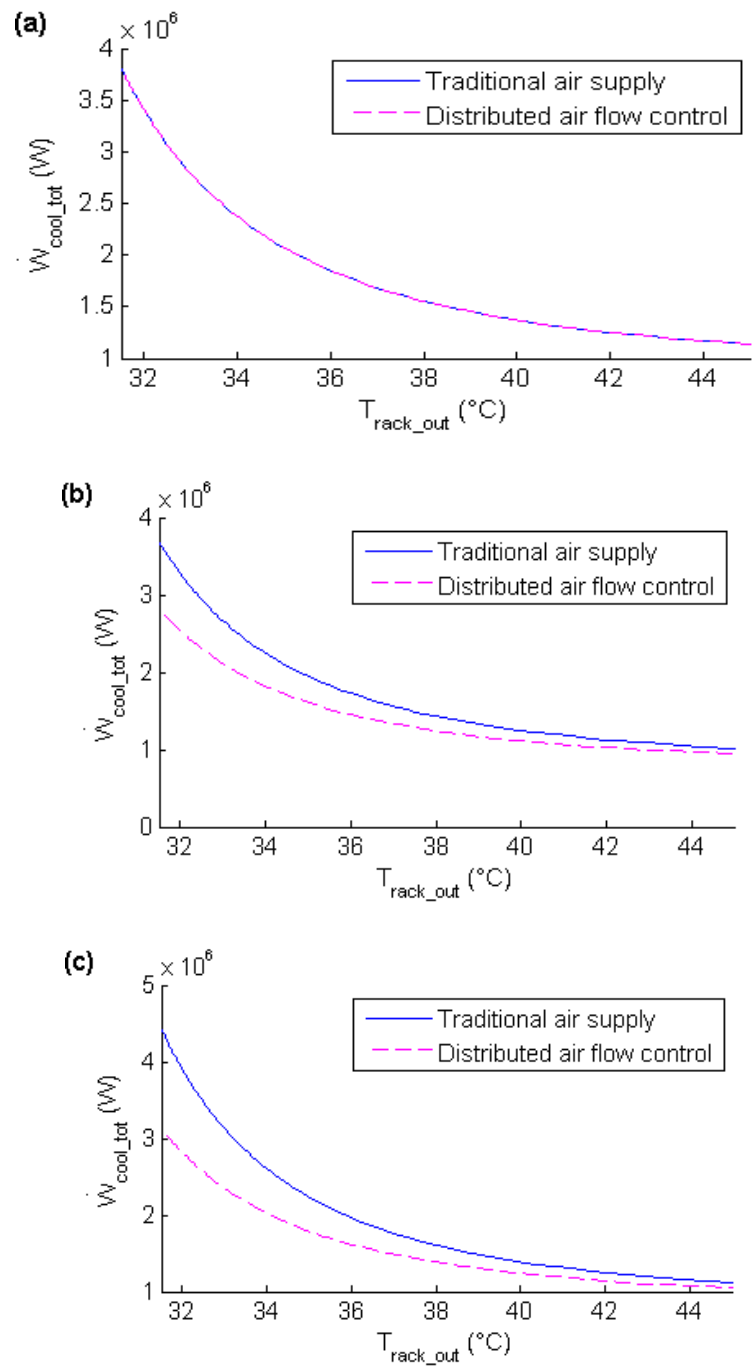

Fig. 3. Total cooling power consumption as a function of the rack outlet temperature for traditional air supply and with distributed air flow control; (a) Even load, (b) Idle servers, (c) Uneven load. 
Due to the distributed air flow control has not been applied in practice, the simulations in this study were made based on available data and information from data center operation. Current study is limited to data center infrastructure management using IT load profiles as inputs for the simulation. IT load variation is depended on different applications and different user behaviors run in cloud. Data center IT load distribution and balancing are a topic related to both data center infrastructure and cloud application. To further improve data center energy efficiency, cross-layer integration and optimization is required for IT load prediction and possible load balancing incorporated to data center cooling and ventilation control.

In next research phase, the model will be extended to incorporate free cooling and it will be used to simulate the data centers with new server rack and ventilation system. An extended dynamic model will be developed for the data center process control and optimization.

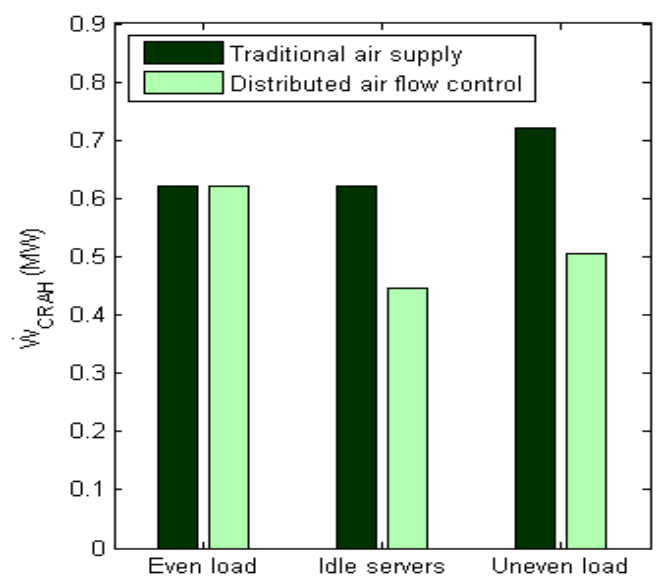

Fig. 4. The CRAH power consumption in MW for all scenarios.

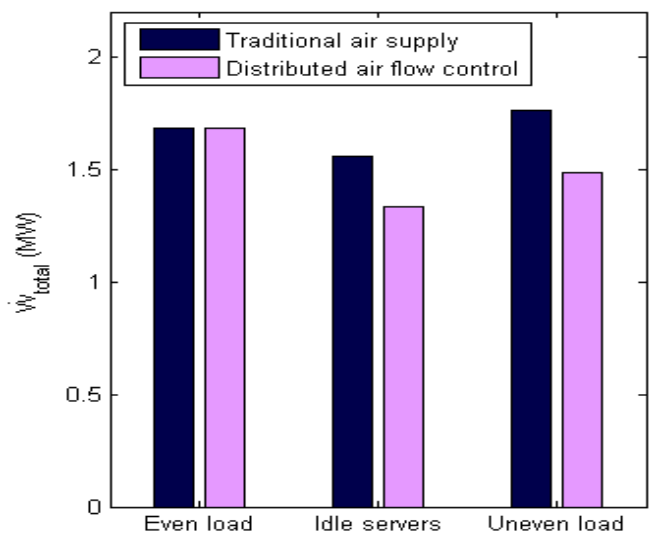

Fig. 5. Total cooling power consumption in MW for all scenarios.

\section{CONCLUSION}

A comprehensive model of the data center cooling power consumption was constructed. Power consumptions of servers, racks, CRAH, chiller, cooling tower, UPS and PDU have been modeled to cover data center design and operation scenarios, Even load, Idle server and Uneven load, with traditional air supply and with a new concept of the distributed air flow control. Simulation results showed that
15 to $16 \%$ of power consumption reduction can be achieved by applying the distributed air flow control for the data centers with idle server and uneven IT load. The developed model can be used for data center design and operation simulation. With extension to dynamic model, it can be used for advanced data center process control.

\section{REFERENCES}

[1] J. G. Koomey, Growth in Data Center Electricity Use 2005 to 2010, Analytics Press, Oakland, 2011.

[2] J. F. Kovar, The 2014 Data Center 100, CRN, 2014.

[3] T. V. Giang, D. Vincent, and B. Seddik, "Data center energy consumption simulator from the servers to their cooling system," in Proc. 2013 IEEE Grenoble Power Tech (POW-ERTECH), June 2013.

[4] Y. Joshi and P. Kumar, "Introduction to data center energy flow and thermal management," Energy E_cient Thermal Management of Data Centers, New York, 2012.

[5] M. Iyengar and R. Schmidt, "Analytical modeling for thermodynamic characterization of data center cooling systems," Journal of Electronic Packaging, vol. 101, June 2009.

[6] R. Schmidt and M. Iyengar, "Thermodynamics of information technology data centers," IBM Journal of Research and Development, vol. 53, no. 3, May 2009.

[7] S. Pelley, D. Meisner, T. F. Wenisch, and F. W. V. Gilder, "Understanding and abstracting total data center power," Workshop on Energy Effcient Design, 2009.

[8] A. H. Beitelmal and C. D. Patel, "A steady-state model for the design and optimization of a centralized cooling system," International Journal of Energy Research, vol. 34, pp. 1239-1248, 2010.

[9] D. W. Demetriou, H. E. Khalifa, M. Iyengar, and R. R. Schmidt, "Development and experimental validation of a thermo-hydraulic model for data centers," HVAC\&R Research, vol. 17, no. 4, pp. 540-555, 2011.

[10] L. Cupertino, G. Da Costa, A. Oleksiak, W. Pi_atek, J. Pierson, J. Salom, L. Sis_o, P. Stolf, H. Sun, and T. Zilio, "Energy-e_cient, thermal-aware modeling and simulation of data centers: The coolemall approach and evaluationresults," Ad Hoc Networks, vol. 25, pp. 535-553, 2015.

[11] Y.A. C. Engel and J. M. Cimbala, Fluid Mechanics Fundamentals and Applications, McGraw-Hill Education, New York, 2nd edition, 2010.

[12] T. V. Giang, D. Vincent, and B. Seddik, "Data center energy consumption simulator from the servers to their cooling system," 2013.

[13] M. Iyengar and R. Schmidt, "Analytical modeling for thermodynamic characterization of data center cooling systems," Journal of Electronic Packaging, vol. 101, June 2009.

[14] A. Shah, C. Patel, C. Bash, R. Sharma, and R. Shih, "Impact of rack level compaction on the datacenter cooling ensemble," Thermal and Thermomechanical Phenomena in Electronic Systems, pp. 1175- 1182.

[15] Y. A. C. Engel and A. J. Ghajar, Heat and Mass Transfer: Fundamentals and Applications, McGraw-Hill Education, New York, 4th edition, 2011.

[16] H. S. Erden and H. E. Khalifa, "Energy and environmental assessment of on-site power and cooling for data centers," HVAC\&R Research, vol. 18, pp. 51-66, 2012.

[17] N. Rasmussen, "Calculating space and power density requirements for data centers," White paper 155, APC Schneider Electrics Data Center Science Center, 2013.

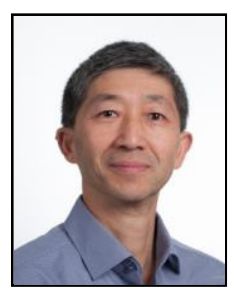

Xiaojing Zhang received the M.S. degree in environmental engineering from China in 1983 and Ph.D. degree in energy technology in 1997 at Royal Institute of Technology, Stockholm. He joined ABB in 1998 and his career included 17 years of industrial experiences in process industry. Dr. Zhang is currently Principal Scientist at ABB Corporate Research, Sweden. 